\title{
Changes in left ventricular function and coronary blood flow velocity during isocapnic hypoxia: A cardiac magnetic resonance imaging study
}

Glen E Foster ${ }^{1 *}$, Zixin Deng ${ }^{2}$, Lindsey M Boulet ${ }^{1}$, Puja K Mehta ${ }^{3}$, Janet Wei ${ }^{3}$, Zhaoyang Fan², Rohan Dharmakumar ${ }^{2}$, C Noel', Bairey Merz ${ }^{3}$, Debiao Li², Michael D Nelson ${ }^{2,3}$

From 19th Annual SCMR Scientific Sessions

Los Angeles, CA, USA. 27-30 January 2016

\section{Background}

Cardiac stress testing is the standard of care for diagnosing ischemic heart disease. Traditional stress testing involves physical or pharmacological stress to induce hyperemia and/or increase myocardial oxygen demand. Physical stress is not possible in $100 \%$ of cases however, and pharmacological stress carries rare but serious risk. We asked whether acute isocapnic hypoxia could be utilized as an alternative cardiovascular stress test.

\section{Methods}

Eight healthy male volunteers $(31+4$ yrs $)$ were exposed to isocapnic hypoxia using a dynamic end-tidal forcing system. Left ventricular function and coronary artery blood flow velocity were measured by MRI (3T, Siemens). The end-tidal partial pressure of oxygen was maintained at $43 \pm 0.3 \mathrm{mmHg}$, while the end-tidal partial pressure of carbon dioxide was controlled at baseline levels. Left ventricular ejection fraction was assessed using a free-breathing cine sequence $(\mathrm{TE} / \mathrm{TR}=1.08$ / $46.74 \mathrm{~ms}$; in-plane spatial resolution $=2.5 \times 2.5 \mathrm{~mm}^{2}$; slice thickness $=8 \mathrm{~mm}$ ). Coronary blood flow velocity was measured in the left anterior descending (LAD), left circumflex (LCX), and left main (LM) coronary arteries using a free-breathing, navigator-gated, Cartesian 2D phase-contrast (PC)-MRI sequence (temporal resolution $=26.4 \mathrm{~ms}$; in-plane spatial resolution $=0.88 \times 0.88$ $\mathrm{mm}^{2}$; slice thickness $=7 \mathrm{~mm}$; VENC $=40-80 \mathrm{~cm} / \mathrm{s}$ in z-direction). Coronary cross-sectional area was assessed in 3 of 8 subjects (all in the left anterior descending coronary artery, LAD), using a 2D balanced steady-state

${ }^{1}$ Center for Heart, Lung, and Vascular Health, University of British Columbia, Kelowna, BC, Canada

Full list of author information is available at the end of the article free precession sequence (ECG-triggered and navigator gated; acquisition only in the quiescent phase; in-plane spatial resolution $=0.85 \times 0.85 \mathrm{~mm}^{2}$; slice thickness $=7 \mathrm{~mm}$ ).

\section{Results}

During hypoxia arterial oxyhemoglobin saturation was reduced to $79 \pm 1 \%$ and heart rate and systolic pressure increased by $47 \%$ and $4 \%$, respectively (all $\mathrm{P}<0.05$ ). Hypoxia increased left ventricular ejection fraction from 66 +1 to $74+1 \%(\mathrm{p}<0.01)$ and rate pressure product from $7057+639$ to $10340+801 \mathrm{mmHg} /$ beat $/ \mathrm{min}(\mathrm{P}<0.01)$. Mean coronary flow velocity increased significantly in seven of the eight subjects ( 5 LAD, increasing from $17.9+$ 2.1 to $25.6+1.2 \mathrm{~cm} / \mathrm{s} ; 1 \mathrm{LCX}$, increasing from 20.1 to 38.8 $\mathrm{cm} / \mathrm{s}$; and $1 \mathrm{LM}$, increasing from 18.6 to $40.0 \mathrm{~cm} / \mathrm{s})$. Poor image quality prevented analysis of coronary flow velocity in 1 subject. The change in coronary flow velocity was proportional to the change in myocardial oxygen demand $(\mathrm{P}=$ $0.26)$. Coronary cross-sectional area was measured in three subjects and found to remain constant $(22.3+4.5$ vs. 22.4 $+5.3 \mathrm{~mm}^{2}, \mathrm{p}=\mathrm{ns}$, baseline vs. hypoxia, respectively).

\section{Conclusions}

This is the first MRI study to simultaneously evaluate cardiac function and coronary blood flow in response to acute isocapnic hypoxia using dynamic end-tidal forcing. The results support the use of hypoxia as a unique cardiovascular stress test. Further investigation is required to determine the feasibility and efficacy of its use in targeted patient populations.

\section{Authors' details}

${ }^{1}$ Center for Heart, Lung, and Vascular Health, University of British Columbia, Kelowna, BC, Canada. ${ }^{2}$ Biomedical Imaging Research Institute, Cedars-Sinai 
Medical Center, Los Angeles, CA, USA. ${ }^{3}$ Heart Institute, Cedars-Sinai Medical Center, Los Angeles, CA, USA.

Published: 27 January 2016

doi:10.1186/1532-429X-18-S1-P126

Cite this article as: Foster et al: Changes in left ventricular function and coronary blood flow velocity during isocapnic hypoxia: A cardiac magnetic resonance imaging study. Journal of Cardiovascular Magnetic

Resonance 2016 18(Suppl 1):P126.

Submit your next manuscript to BioMed Central and take full advantage of:

- Convenient online submission

- Thorough peer review

- No space constraints or color figure charges

- Immediate publication on acceptance

- Inclusion in PubMed, CAS, Scopus and Google Scholar

- Research which is freely available for redistribution

Submit your manuscript at www.biomedcentral.com/submit 